\title{
INTERCULTURALIDADE, ENSINO DE INGLÊS COMO LÍNGUA FRANCA E A BASE NACIONAL COMUM CURRICULAR
}

\author{
Leandro Santos Silva* \\ Sheila Rocha Ladeia* \\ Giêdra Ferreira Cruz ${ }^{* * *}$
}

RESUMO: Este artigo, que tem como base teórica e metodológica a Linguística aplicada, objetiva discutir a proposta Base Nacional Comum Curricular (BNCC), especificamente no que se refere ao ensino e a aprendizagem de língua inglesa e, para tal, termos como "língua", "Cultura", "Inglês como língua franca" e "interculturalidade", abordados no texto como componentes essenciais a uma Educação de caráter formativo, serão analisados. Essa análise tem como princípio norteador verificar em qual perspectiva tais termos são utilizados na BNCC. Assim, a partir de uma pesquisa bibliográfica e documental, esperamos que os princípios subjacentes aos termos, utilizados ao longo do documento oficial, sejam realmente introduzidos nas salas de aulas dos estudantes da educação básica.

PALAVRAS-CHAVE: BNCC; Inglês como Língua Franca; Interculturalidade;.

\section{Introdução}

De acordo com Cruz (2016), depois da Segunda Guerra Mundial, os Estados Unidos adquiriram o status de superpotência hegemônica e, consequentemente, a sua língua

\footnotetext{
* Mestrando em Letras: Cultura, Educação e Linguagem pela Universidade Estadual do Sudoeste da Bahia (Uesb).

** Mestranda em Letras: Cultura, Educação e Linguagem pela Universidade Estadual do Sudoeste da Bahia (Uesb).

${ }^{* * *}$ Doutora em Língua e Cultura pela Universidade Federal da Bahia (Ufba). Professora Adjunta da Universidade Estadual do Sudoeste da Bahia (Uesb).
} 
espalhou-se com mais força pelo mundo como uma das mais fortes marcas de sua expansão, transformando-se na "língua de uso comum da chamada era da informação, alcançando, nas últimas décadas, principalmente devido à posição hegemônica dos Estados Unidos, com o seu poderio político-militar e avanço tecnológico, expansão jamais vista” (SIQUEIRA, 2011, p. 334).

As discussões acerca da importância do domínio de uma língua estrangeira sempre fizeram parte do cenário criado pela globalização. No Brasil, não poderia ser diferente e, nos anos de 2015 e 2016, essas discussões tomaram proporções ainda maiores, logo após o Ministério da Educação (MEC) enviar ao Conselho Nacional de Educação (CNE) a proposta de direitos e objetivos de aprendizagem e desenvolvimento para alunos da Educação Básica. Essa proposta seria conhecida como a Base Nacional Comum Curricular $(\mathrm{BNCC})^{1}$.

A partir de um estudo de Silva et al (2017) realizado em documentos oficiais, que dispõem sobre as orientações e caminhos a serem seguidos pelo sistema educacional brasileiro,especificamente as Leis de Diretrizes e Bases (LDB), desde 1961 até os dias atuais, que este estudo objetiva verificar como a BNCC compreende o ensino de língua inglesa, bem como, observar as concepções sobre o ensino/aprendizagem de inglês contidas nesse documento.

Tomando como objeto de estudo aquilo que concerne ao Ensino/aprendizagem de Língua Inglesa, doravante LI, este trabalho propõe uma discussão norteada pela seguinte pergunta: Quais são as concepções de língua/cultura, no novo BNCC, voltadas para o ensino/aprendizagem de língua inglesa? Ressaltamos que antes de nos debruçarmos sobre tal discussão, retomamos dados extraídos do estudo de Silva et al (2017), que

\footnotetext{
${ }^{1}$ De acordo com informações disponíveis em http://basenacionalcomum.mec.gov.br/\#/site/inicio A Base Nacional Comum Curricular (BNCC) é um documento de caráter normativo que define o conjunto orgânico e progressivo de aprendizagens essenciais que todos os alunos devem desenvolver ao longo das etapas e modalidades da Educação Básica.
} 
mostram como as Políticas Linguísticas lidavam/lidam com o ensino da LI, suas deliberações a respeito do ensino dessa língua no território nacional e quais as principais mudanças ocorridas nesse setor ao longo dos anos. Assim sendo, o tomamos como ponto de partida para nosso estudo atual.

Quanto a sua organização, este artigo é composto por duas seções. Na primeira delas, com base no estudo de Silva et al (2017), já mencionado, retomamos o histórico do ensino de línguas no Brasil, desde o ano de 1837, quando ele se inicia, e ainda trazemos uma discussão a respeito do caráter político da Língua, deixando claro que o ensino de línguas desde o início sempre esteve atrelado à questões políticas. Em seguida, recuperamos a análise das duas LDB já vigentes no País: LDB de 1961 e 1971, traçando um paralelo sobre a importância que o ensino de LI tinha para o Governo, nas diferentes épocas nas quais vigoravam/vigoram as LDB. Depois, reavemos a LDB 9394/96, quando verificamos o retorno do ensino obrigatório de Língua Estrangeira.

Na segunda seção, discutimos os dois primeiros parágrafos da BNCC, que discorrem sobre o componente curricular: Linguagens, em específico o componente Língua Inglesa, destacando os termos "língua", "Cultura", "Inglês como língua franca" e "interculturalidade" abordados no texto como componentes essenciais a uma Educaçãode caráter formativo, proposta pela nova BNCC.

\section{Histórico do ensino de línguas no Brasil}

Silva et al (2017) iniciam o texto mencionando Oliveira (2009), que sinaliza que suscitar a problematização da função do ensino de línguas nos dias atuais, pode gerar a falsa ilusão de que esse fenômeno seja recente, quando na verdade o interesse por esse tipo de ensino remota o século IX D.C. Para os autores, a política linguística é parte constituinte do ensino de língua, tanto materna, como estrangeira. Nessa direção, Rajagopalan (2013) afirma que,

Como uma área de estudos reconhecida e institucionalizada como tal, a política linguística tem mais ou menos meio século de existência. Mas a verdade é que, conforme já salientamos, a questão 
política esteve presente o tempo todo ao longo da história, influenciando diretamente a tomada de decisões importantes no que tange às políticas educacionais (RAJAGOPALAN, 2013, p. 145).

Isso implica dizer que meio século atrás e, ainda hoje, a Língua ( e tudo o que está em seu entorno: ensino, aprendizagem, objetivos, por exemplo) sempre esteve envolta pela política e pelo poder, como menciona Rajagopalan (2013, p. 145) ao comentar a frase de Joseph (2006) quando esse afirma que “a linguagem é política de cabo a rabo",

[...] o autor não está dizendo que a linguagem não comporta uma dimensão política em acréscimo a todo o resto que se crê que ela possua; ele está defendendo que a linguagem é constitutivamente e, por conseguinte, indissociavelmente, política (RAJAGOPALAN, 2013, p. 145).

Nesse caso, isso demonstra que, mesmo antes da existência de quaisquer leis que regessem o ensino/aprendizagem de uma língua, ela já possuía no DNA de sua conjuntura traços marcantes e até mesmo dominantes de uma concepção política: língua, política e poder, jamais deixaram de ser uma tríade e, seu surgimento, propagação e desenvolvimento sempre se apoiaram uns nos outros.

Segundo PAIVA (2003), o interesse e o envolvimento do ensino de Línguas têm seu início no ano de 1837, com a criação do Colégio Pedro II. Naquela época, o ensino oficial de línguas priorizava não apenas as línguas clássicas como o Latim e o Grego, mas disputavam espaço com mais três outras línguas: o Francês, o Inglês e também o Alemão. Todas, obrigatoriamente, faziam parte do campo de ensino de línguas. Até mesmo o Italiano tinha sua fatia, já que entrava na grade como facultativo. Esses dados demonstram o apogeu do ensino de Línguas Estrangeiras na escola pública do Brasil. Contudo, ainda Paiva (2003) salienta que essa realidade começa a sofrer sérias mutações quando, logo após a instauração do governo republicano, retira-se, em 1915 o grego do sistema de ensino, e o francês passa a ser priorizado em detrimento do Inglês que, na época, não oferecia tanta influência cultural e científica ao Brasil quanto a França. O que só viria a mudar com o surgimento do cinema falado nos anos 20 e após o início da Segunda Guerra Mundial, quando os Estados Unidos assumem posição hegemônica no mundo. 


\section{LBD de 1961 e a LDB de 1971}

Em relação à LEI No 4.024, sancionada em 20 de dezembro de 1961 em conjunto com a LEI N. 5.692, de 11 de agosto de 1971, constatamos que, em ambas, o Ensino de Língua Estrangeira deixa de ter seu espaço garantido na matriz curricular, passando a ser uma das disciplinas optativas, o que aos olhos de muitos alunos, passou a ser encarada como um papel secundário, não reprovatório.

É interessante perceber que, ao longo dos textos oficiais citados, o adjetivo optativo aparece com certa frequência, quando se refere ao currículo disciplinar a ser adotado. Vejamos alguns dos exemplos:

$\int 1^{\circ}$ Ao Conselho Federal de Educação compete indicar, para todos os sistemas de ensino médio, até cinco disciplinas obrigatórias, cabendo aos conselhos estaduais de educação completar o seu número e relacionar as de caráter optativo que podem ser adotadas pelos estabelecimentos de ensino.

Art. 40. Respeitadas as disposições desta lei, compete ao Conselho Federal de Educação, e aos conselhos estaduais de educação, respectivamente, dentro dos seus sistemas de ensino:

Organizar a distribuição das disciplinas obrigatórias, fixadas para cada curso, dando especial relevo ao ensino de português;

Permitir aos estabelecimentos de ensino escolher livremente até duas disciplinas optativas para integrarem o currículo de cada curso;

$\int 2^{\circ}$ Entre as disciplinas e práticas educativas de caráter optativo no $1^{\circ}$ e $2^{\circ}$ ciclos, será incluída uma vocacional, dentro das necessidades e possibilidades locais. Art. 45. No ciclo ginasial serão ministradas nove disciplinas.

Parágrafo único. Além das práticas educativas, não poderão ser ministradas menos de 5 nem mais de 7 disciplinas em cada série, das quais uma ou duas devem ser optativas e de livre escolha do estabelecimento para cada curso.

Art. 46. Nas duas primeiras séries do ciclo colegial, além das práticas educativas, serão ensinadas oito disciplinas, das quais uma ou duas optativas, de livre escolha pelo estabelecimento, sendo no mínimo cinco e no máximo sete em cada série (BRASIL, 1961) 
Segundo Oliveira (2009) o ensino/aprendizagem de línguas estão interligados aos objetivos e ao contexto histórico de uma nação, o que nos leva a refletir: com um mundo que acabara de sair de uma Segunda Guerra Mundial e com ele a existência de uma diáspora sem precedentes; com o Brasil trabalhando na construção, expansão e consolidação dos laços culturais e econômicos com os Estados Unidos da América; com a necessidade e desejo de aprender inglês ganhando proporções gigantescas por parte dos jovens e trabalhadores que julgavam estar implementando seu currículo; com a chegada de milhares de japoneses, italianos, alemães entre outras nações ao nosso território. A partir desse posicionamento de Oliveira (2009), Silva et al $(2017$, p.6) questionam "com qual objetivo aqueles que formularam as Leis de Diretrizes e Bases da educação do nosso País, naquela época, resolveram retirar a obrigatoriedade do ensino de línguas estrangeiras do sistema público educacional?”. E prosseguem afirmando que Paiva (2003) pontua a desobrigatoriedade do ensino de Línguas nas escolas públicas em contraponto com a procura cada vez maior pelo ensino de línguas, foi um dos principias motivos para o aumento dos cursos particulares de ensino de língua estrangeira e um ponto extremamente negativo para o sistema educacional brasileiro que, nesse sentido, serviu para aumentar ainda mais a desigualdade social em nosso país. Para a autora,

Apesar de todos os setores da sociedade reconhecerem a importância do ensino de língua estrangeira, as políticas educacionais nunca lhe asseguraram uma inserção de qualidade em nossas escolas. Em busca dessa qualidade, as classes privilegiadas sempre procuraram garantir a aprendizagem de línguas nas escolas de idiomas ou com professores particulares, mas os menos favorecidos continuaram à margem desse conhecimento (PAIVA, 2003, p.57).

Compreendemos que esse quadro, apontado por Paiva (2003), continua o mesmo, pois é possível perceber, no processo ensino/aprendizagem do inglês, o fato de que, para muitos, a escola pública não parece ser o melhor lugar para se aprender uma nova língua. No entanto, os problemas que permeiam o ensino da língua inglesa Brasil certamente ultrapassam o âmbito da escola pública, apesar dos discursos que pontuam a relevância desse idioma para o crescimento social e profissional dos indivíduos. Assim, por mais 
perceptível que pareça a importância do inglês na sociedade atual, a realidade é que esse processo de ensino encontra-se mergulhado em incertezas e conflitos.

\section{Lei $\mathrm{N}^{\circ} 9.394$ de 20 de dezembro de 1996}

Em relação à LDB de 1996, analisada por Silva et al (2017), concordamos que ela devolve à educação básica pública o ensino de línguas estrangeiras, ao sinalizar a obrigatoriedade da inclusão de pelo menos uma língua adicional. "E, com isso, deixa claro que os currículos escolares podem escolher mais uma língua, se assim quiserem, com a ressalva de que esta deveria ser escolhida de acordo as possibilidades da instituição” (p. 7), como pode ser observado, a seguir,

$\int 5^{\circ} \mathrm{Na}$ parte diversificada do currículo será incluído, obrigatoriamente, a partir da quintasérie, o ensino de pelo menos uma língua estrangeira moderna, cuja escolha ficará acargo da comunidade escolar, dentro das possibilidades da instituição (BRASIL,1996).

Ao mencionar que a "escolha ficará a cargo da comunidade escolar", fica implícito que compete ao Estado o dever de promover essas "possibilidades", ou seja, de gerar as condições necessárias para que essa escola exista, a fim de fazer cumprir o que a Constituição institui como seu dever, que é o oferecimento de uma educação de qualidade.

Nessa linha de pensamento, Silva et al (2017) mencionam que o idioma inglês não aparece citado como obrigatório, mas fica subtendido pelo fato de ser, sobretudo na atualidade a Língua que rege o mundo dos negócios e das telecomunicações e, por isso, o idioma mais falado no planeta por falantes não nativos.

Na segunda seção, a seguir, retomamos na íntegra, os dois primeiros parágrafos referentes ao texto sobre o componente curricular Língua Inglesa, encontrado na nova BNCC, objetivando analisar as concepções de língua/cultura voltadas para o ensino/aprendizagem de língua inglesa. 


\section{A nova base nacional comum curricular e o ensino de inglês}

Língua inglesa

Aprender a língua inglesa propicia a criação de novas formas de engajamento e participação dos alunos em um mundo social cada vez mais globalizado e plural, em que as fronteiras entre países e interesses pessoais, locais, regionais, nacionais e transnacionais estão cada vez mais difusas e contraditórias. Assim, o estudo da língua inglesa possibilita aos alunos ampliar horizontes de comunicação e de intercâmbio cultural, científico e acadêmico e, nesse sentido, abre novos percursos de acesso, construção de conhecimentos e participação social. É esse caráter formativo que inscreve a aprendizagem de inglês em uma perspectiva de educação linguística, consciente e crítica, na qual as dimensões pedagógicas e políticas são intrinsecamente ligadas.

Ensinar inglês com essa finalidade tem, para o currículo, duas implicações importantes. A primeira é que ela obriga a rever as relações entre língua, território e cultura, na medida em que os falantes de inglês já não se encontram apenas nos países em que ela tem o caráter de língua oficial. Trata-se, portanto, de definir a opção pelo ensino da língua inglesa como língua franca, uma língua de comunicação internacional utilizada por falantes espalhados no mundo inteiro, com diferentes repertórios linguísticos e culturais. Essa perspectiva permite questionar a visão de que o único inglês correto - e a ser ensinado - é aquele falado por estadunidenses ou britânicos, por exemplo. Desse modo, o tratamento do inglês como língua franca o desvincula da noção de pertencimento a um determinado território e, consequentemente, a culturas típicas de comunidades específicas. Esse entendimento favorece uma educação linguística voltada para a interculturalidade, isto é, para o reconhecimento das (e o respeito às) diferenças, e para a compreensão de como elas são produzidas.

Voltamos nosso olhar, neste momento, para o recorte desses dois parágrafos, que serão analisados em cinco excertos, por se tratarem dos objetivos, da importância e da forma como a Língua Inglesa deverá ser compreendida na Educação básica.

\section{Excerto 1:}

Aprender a língua inglesa propicia a criação de novas formas de engajamento e participação dos alunos em um mundo social cada vez mais globalizado e plural, em que as fronteiras entre países e 
interesses pessoais, locais, regionais, nacionais e transnacionais estão cada vez mais difusas e contraditórias.

Teóricos como Phillipson (1992), Pennycook (1994) e Canagarajah (1999, 2005) fazem reflexões importantes sobre a natureza sócio-histórica da expansão da língua inglesa pelo mundo, que nos permitem entender por um lado, pela "percepção e a honestidade intelectual de denunciar e questionar o papel colonialista da língua inglesa em detrimento de outros idiomas e culturas e, por outro lado, de trazer o referido discurso para a área da Linguística Aplicada" (SCHMITZ, 2004, p. 226).

Nessa direção, Cox e Assis-peterson (2001) afirmam que

Quem ensina não pode deixar de se colocar criticamente em relação ao discurso dominante que representa a internacionalização do inglês como um bem, um passaporte para o primeiro mundo. Quem ensina inglês não pode deixar de considerar as relações de seu trabalho com a expansão da língua, avaliando criticamente as implicações de sua prática na produção e reprodução das desigualdades sociais. Quem ensina inglês não pode deixar de se perguntar se está colaborando para perpetuar a dominação de uns sobre os outros (COX; ASSIS-PETERSON, 2001, p. 20-21).

Nesse sentido, compreendemos que é preciso que os professores ajudem o estudante a falar inglês como forma de ascensão social, profissional ou de prazer pessoal, como um direito à sua "cidadania linguística", em outras palavras, o aluno precisa aprender inglês para chegar aonde ele deseja "em um mundo social cada vez mais globalizado e plural".

\section{Excerto 2:}

Assim, o estudo da língua inglesa possibilita aos alunos ampliar horizontes de comunicação e de intercâmbio cultural, científico e acadêmico e, nesse sentido, abre novos percursos de acesso, construção de conhecimentos e participação social. É esse caráter formativo que inscreve a aprendizagem de inglês em uma perspectiva de educação linguística, consciente e crítica, na qual as dimensões pedagógicas e políticas são intrinsecamente ligadas. 
Quando a BNCC enfatiza a importância da língua inglesa para a ampliação de intercâmbio cultural e para a apropriação de conhecimentos científicos, ela reconhece o quão essencial esse idioma se tornou para o desenvolvimento dos mais diversos campos comerciais, acadêmicos, profissionais e culturais. A aprendizagem do inglês além de proporcionar grandes oportunidades de ampliação de conhecimento e de visão de mundo, ainda se apresenta como um ponto relevante para transformação social e pessoal.

O desafio da aprendizagem de uma nova Língua envolve o desafio de conhecer uma nova cultura e, mais ainda, abrir-se para o aprendizado dessa nova língua/cultura é se permitir não apenas ser tocado por ela, mas indubitavelmente também ser, por ela, transformado. Assim, nessa perspectiva que torna impossível dissociar língua e cultura, Dourado e Poshar (2010) afirmam que,
A indissociabilidade entre língua e cultura é cada vez mais visível no mundo globalizado, no qual urge uma educação intercultural em que a cultura e a língua caminhem lado a lado como fatores fundamentais na promoção de uma convivência compartilhada no planeta (DOURADO; POSHAR, 2010, p.34).

Compreendemos esse posicionamento, pois consideramos que a aprendizagem de uma língua separada de sua cultura, seria o mesmo que aprender uma língua esvaziada de sentido. Como poderíamos interpretar um discurso se não reconhecêssemos as representações a ele subjacentes?

\section{Excerto 3:}

Ensinar inglês com essa finalidade tem, para o currículo, duas implicações importantes. A primeira é que ela obriga a rever as relações entre língua, território e cultura, na medida em que os falantes de inglês já não se encontram apenas nos países em que ela tem o caráter de língua oficial. 
Ensinar língua envolve questões que vão muito além de entender regras gramaticais que se fundamentam em estruturas linguísticas, mas, como afirma Bohn (2009)

[...] envolve o desenvolvimento de competências linguísticas, isto é, a capacidade de utilizar um conjunto de regras-conhecimentos fonológicos, morfológicos, sintáticos e semânticos, coordenadas com normas de uso sociolinguístico determinadas pelo contexto em que a ação linguageira se realiza (BOHN, 2009, p.169).

O cumprimento desses aspectos, descritos por Bohn (2009), que envolvem o processo de aprendizagem da língua inglesa, poderá conceder ao aprendiz o desenvolvimento das habilidades fundamentais em situações cotidianas e poderá cooperar para o aprimoramento da língua alvo, além de ampliar a sua participação social. Assim sendo, acreditamos que quando se leva em consideração aspectos linguísticos e culturais da aprendizagem de língua inglesa, pode acarretar uma mudança nas práticas nos ambientes de aprendizagem, proporcionando, assim, reflexão sobre o progresso de novos modos de ensinar a língua inglesa, além de ajudar na formação de cidadãos autônomos.

Como afirma Paiva (2009, p.32), “ a língua deve ser ensinada em toda sua complexidade comunicativa, sem restringir seu estudo a uma tecnologia (leitura) ou a aspectos apenas formais (gramática). A língua deve fazer sentido para o aprendiz em vez de ser apenas um conjunto de estruturas gramaticais". E isso se torna essencial para "os falantes de inglês [que] já não se encontram apenas nos países em que ela tem o caráter de língua oficial".

\section{Excerto 4:}

Trata-se, portanto, de definir a opção pelo ensino da língua inglesa como língua franca, uma língua de comunicação internacional utilizada por falantes espalhados no mundo inteiro, com diferentes repertórios linguísticos e culturais. Essa perspectiva permite questionar a visão de que o único inglês correto - e a ser ensinado - é aquele falado por estadunidenses ou britânicos, por exemplo. 
Jenkins (2006) conceitua inglês como língua franca (ILF) como uma língua de contato entre linguaculturas que não compartilham a mesma língua materna. Assim, para a autora, o inglês serve como língua franca entre os falantes não nativos de inglês. Em outras palavras, o inglês como língua franca é realizado entre falantes de diferentes experiências culturais e de nacionalidades diversas. Essa perspectiva amplia nossa visão em relação ao ensino/aprendizagem de língua inglesa e, coadunando com as palavras de Lima (2010, p. 90), "o ensino de língua estrangeira deve ser encarado na esfera de objetivos pedagógicos mais amplos, que envolvem questões de natureza ética, ideológica, política etc.”.

Assim sendo, entendemos a necessidade do trabalho com a língua inglesa como uma forma de se repensarem os papéis de alunos e de professores dentro e fora da sala de aula e, para tal, precisamos trabalhar a língua inglesa na perspectiva de ILF, ou seja, em direção de uma tomada de consciência acerca dos muitos ingleses existentes e da força política, linguística e cultural que envolve esse idioma (CRUZ, 2016).

De acordo com House (2012, p. 364), as mais relevantes particularidades do ILF “[...] são sua enorme flexibilidade funcional, sua variabilidade e expansão pelas diferentes áreas linguísticas, geográficas e culturais [...]”2. Assim sendo, o princípio que subjaz o ILF é a capacidade de seus usuários interagirem, comunicando entre si, ou seja, "aquele que conserva uma identidade nacional e recorre a estratégias de negociação para garantir a comunicação com o mundo". (ALVES, 2015, p.17). Logo a relação língua/cultura se torna algo complexo de diferir, pois não há cultura que sobrepõe sobre a outra, mas igualmente são conservadas e respeitadas, o que ocorre é a necessidade de compreensão dos contatos entre as línguas e os enredos socioculturais em que elas são aprendidas e utilizadas que levem em conta a fluidez, diversidade e adaptação (BAKER, 2009).

${ }^{2}[\ldots]$ are its enormous functional flexibility, its variability and spread across many different linguistic, geographical and cultural areas $[\ldots]$ 


\section{Excerto 5:}

Desse modo, o tratamento do inglês como língua franca o desvincula da noção de pertencimento a um determinado território e, consequentemente, a culturas típicas de comunidades específicas. Esse entendimento favorece uma educação linguística voltada para a interculturalidade, isto é, para o reconhecimento das (e o respeito às) diferenças, e para a compreensão de como elas são produzidas.

Nessa direção, Rajagopalan (2009, p. 46) afirma que o professor deve ter o cuidado de "desvincular a língua desse ou daquele país", enfatizando que quando se estuda o inglês, esse idioma não pode estar vinculado somente aos Estados Unidos e/ou à Inglaterra. Em outras palavras, utilizar a língua franca significa ter amplo acesso ao mundo e ela pertence a todos que fazem uso dela. Ainda nessa perspectiva, Rajagopalan (2004) defende que,

Uma das maneiras pela qual as identidades acabam sofrendo o processo de renegociação, de realinhamento, é o contato entre as pessoas, entre os povos, entre as culturas. É por esse motivo que se torna cada vez mais urgente entender o processo de 'ensino-aprendizagem' de uma língua "estrangeira” como um processo de redefinição de identidades... Logo, quem transita entre diversos idiomas, está redefinindo sua própria identidade. Dito de outra forma, quem aprende uma língua nova está se redefinindo como uma nova pessoa (RAJAGOPALAN, 2004, p. 69).

Corroboramos com o pensamento do autor, pois, além de compreendermos o ensino aprendizagem de línguas dentro de uma perspectiva sociocultural, estaremos, por fim, realizando uma educação realmente intercultural. Compreendida por Guilherme (2002, p.197) como a "capacidade de interagir com eficácia com pessoas de culturas que nós reconhecemos como diferentes da nossa".

Quando nos referimos a uma educação intercultural, especificamente para o ensino de Línguas, autores tais como, Crystal (1997); Pennycook (1994); Phillipson (1992); Rajagopalan (2004); Robbins (1997) pontuam a respeito da necessidade de problematizar 
o neo-colonialismo que geralmente aparece dissolvido na Língua, disseminando os valores norte-americanos e ocidentais. Para reforçar seus argumentos, esses autores discutem o conceito do inglês nativo, assim como o conceito de World English, desterritorializando o domínio da Língua e procurando desconstruir o quadro de imperialismo linguístico e cultural, até então sob o domínio britânico e norte-americano.

\section{Considerações finais}

Para Silva et al (2017),

Não é difícil compreender que os aspectos socioculturais não são apenas partes constituintes no processo das relações interpessoais, mas que, de forma relevante, eles se tornam essenciais para que essas relações possam existir. E quando nos referimos a pessoas pertencentes a comunidades de línguas diferentes então, não se pode conceber qualquer tipo de interação amistosa sem o reconhecimento e o respeito a esses aspectos.

Essa afirmação ainda é mais poderosa quando se trata do ensino e aprendizagem de línguas. Se considerarmos que esse tipo de ensino envolve um processo global, logo, apenas a aprendizagem de vocabulários e de regras gramaticais se tornam, em absoluto, ineficientes. Faz-se necessário entender esse mundo a qual pertence à língua alvo, agir nele, envolver-se nele e, envolvê-lo, até ele não lhe ser mais estranho e vice-versa (SILVA ET AL, 2017).

O estudo de Silva et al. (2017) revelou caminhos percorridos pelo ensino da Língua Inglesa no Brasil, sinalizando o modo como as Políticas Educacionais deliberavam e ainda deliberam sobre as prioridades, os objetivos e os direcionamentos do ensino/aprendizagem de Língua Inglesa. Ainda mostrou que, com a implementação da nova BNCC, o governo decidiu regulamentar o ensino da língua inglesa como obrigatório, trazendo nos textos relativos a área de linguagens a indicação da Educação Intercultural para esse ensino. Desse modo, consideramos a forma de vislumbrar o ensino e a aprendizagem de Língua Inglesa, na BNCC, como um avanço, já que termos essenciais, como "língua", "cultura", "Inglês como língua franca" e "interculturalidade", se inscrevem em seu centro para enfatizar a 
maneira como a Língua Inglesa deverá ser ensinada/aprendida na Educação Básica, visando o caráter formativo do estudante.

Para Mendes (2007), o inglês representa uma multiplicidade de culturas, e que uma educação baseada na interculturalidade promove o desenvolvimento do respeito à cultura do outro, e concomitantemente, a sua própria, fazendo com que os aprendizes da língua se tornem sensíveis ao fato de que cada pessoa, mesmo que de diferente cultura, se utiliza de cada uma delas com sua especificidade e cientes de que todos fazem parte da comunidade global.

Reconhecendo que fazemos parte dessa comunidade global, discutimos aqui sobre o inglês em uma perspectiva de língua franca, enfatizando o fenômeno da expansão global da língua inglesa. Por isso, a importância de se pensar o ILF está no fato de reduzir a tensão de se enxergar a aprendizagem de inglês como uma submissão à cultura do outro, possibilitando o estabelecimento de objetivos voltados muito mais para as reais necessidades dos estudantes.

Desse modo, reiteramos, com a análise desses cinco excertos, que houve um avanço da concepção de língua/cultura na BNCC, em relação aos documentos anteriores. No entanto, muito ainda precisa ser melhorado para que os nossos estudantes possam ter acesso a uma formação crítico-reflexiva. Assim, esperamos que os princípios subjacentes aos termos "língua", "Cultura", "Inglês como língua franca" e "interculturalidade", utilizados ao longo do documento oficial, sejam realmente introduzidos nas salas de aulas dos estudantes da educação básica.

\section{INTERCULTURALITY, TEACHING OF ENGLISH AS A LINGUA FRANCA AND A COMMON CURRICULAR NATIONAL BASIS}

ABSTRACT: This article, whose theoretical and methodological basis is Applied Linguistics, aims to discuss the National Curricular Common Base (BNCC), specifically with regard to English language teaching and learning and, for this purpose, terms such as "language" "Culture", "English as a lingua franca" and "interculturality", addressed in the text 
as essential subjects of an education of a formative nature, will be analyzed. This analysis has as guiding principle to verify in which perspective such terms are being used in BNCC. Thus, from a bibliographical and documentary research, we hope that the principles underlying the terms, used throughout the official document, are actually introduced in the classrooms of students of Basic Education.

KEYWORDS: BNCC; English as a Lingua Franca; Interculturality.

\section{REFERÊNCIAS}

ALVES. P.C.R. O ensino de inglês como lingua desnacionalizada e a dimensão cultural: a visão de professores formadores. 2015. 231fl Dissertação (Mestrado em Língua e Cultura), Universidade Federal da Bahia, Salvador, 2015.

BAKER, W. Intercultural awareness and intercultural communication through English: an investigation of Thai English language users in higher education. 2009. 365f. Tese (Doutorado em Artes e Ciências Sociais), Universidade de Southampton, UK, 2009.

BOHN, H. I. O método "soberano" para o ensino e aprendizagem da língua inglesa. In: LIMA, D. C. (Org.). Ensino e aprendizagem de lingua inglesa: conversas com especialistas. São Paulo: Parábola Editorial, 2009, p. 169-78.

BRASIL. Lei n. 9394, de 20 de dezembro de 1996. Estabelece as diretrizes e bases da educação nacional. Disponível em: http://www.planalto.gov.br/ccivil_03/LEIS/19394.htm.

Acesso em: 20 de agosto 2017.

BRASIL. LEI N. 4.024, de 20 de dezembro de 1961. Fixa as Diretrizes e Bases da Educação Nacional. Disponível em: http://www2.camara.leg.br/legin/fed/lei/1960-1969/lei-402420-dezembro-1961-353722-publicacaooriginal-1-pl.html. Acesso em 20 de agosto de 2017.

BRASIL. LEI N ${ }^{\circ}$ 5.692, DE 11 DE AGOSTO DE 1971. Fixa Diretrizes e Bases para o ensino de $1^{\circ}$ e $2^{\circ}$ graus, e dá outras providências.Disponível em: http://www2.camara.leg.br/legin/fed/lei/1960-1969/lei-4024-20-dezembro-1961-353722-publicacaooriginal-1-pl.html. Acesso em 20 de agosto de 2017.

CANAGARAJAH, A. S. Resisting linguistic imperialism in English teaching. Oxford: Oxford University Press, 1999.

CANAGARAJAH, S. Reconstructing local knowledge, reconfiguring language studies. In: CANAGARAJAH, S. (Org.). Reclaiming the Local in Language Policy and Practice. Mawhaw, New Jersey: Lawrence Erlbaum Associates, Publishers.

COX, M. I. P.; ASSIS-PETERSON, A. A. O professor de Inglês: entre a alienação e a emancipação. Linguagem e Ensino, v. 4, n. 1, p. 11-36, 2001. 
CRYSTAL, D. English as a Global Language. Cambridge: Cambridge University Press, 1997.

CRUZ, G. F. Inglês como língua global: Reflexões sobre o ensino/aprendizagem. In: Fólio: Revista de Letras. Vol. 8, No 1 (2016). v.8, n.1 p. 315-331.

DOURADO, M. R.; POSHAR, H. A. A cultura na educação linguística no mundo globalizado. In: SANTOS, P.; ALVAREZ, M. L. O. (Org.). Língua e cultura no contexto de português língua estrangeira. Campinas, SP: Pontes Editores, 2010. p.33-52.

GUILHERME, M. Comunicação Intercultural, Globalidade e Diversidade. Revista de Humanidades e Tecnologias. Dossier Línguas e Culturas, 6/7/8, 2002, p. 195-198.

HOUSE, J. English as a global lingua franca: A threat to multilingual communication and translation? Language Teaching, v. 47, n. 3, p. 363-376, 2012.

JENKINS, J. English as a lingua franca: attitude and identity. Oxford: Oxford University Press, 2006.

OLIVEIRA, L. A. Ensino de língua estrangeira para jovens e adultos na escola pública. In: LIMA, D. C. (Org.). Ensino e aprendizagem de língua inglesa: conversa com especialistas. São Paulo. Parábola Editorial, 2009. p. 21-30.

MENDES, E. A perspectiva intercultural no ensino de línguas: uma relação "entre culturas". In: ALVAREZ, M. L. O.; SILVA, K. A. da (Org.). Linguística aplicada: múltiplos olhares. Campinas: Pontes, 2007. p. 119-139.

PAIVA, V. L. M. O. A LDB e a legislação vigente sobre o ensino e a formação de professor de língua inglesa. In: STEVENS, C. M. T.; CUNHA, M. J. C. (Org.). Caminhos e colheitas: ensino e pesquisa na área de inglês no Brasil. Brasília: Editora UNB. 2003. Disponível em: <http://www.veramenezes.com/publicacoes.htm. Acesso em 15 de junho de 2018.

PAIVA, V. L. M. O. O ensino de língua estrangeira e a questão da autonomia. In: LIMA, D. C. (Org.) Ensino e aprendizagem de lingua inglesa: conversa com especialistas. São Paulo. Parábola Editorial, 2009, p. 31-38.

PENNYCOOK, A. The cultural politics of English as an international language. Essex: Pearson Longman, 1994.

PHILLIPSON, R. Linguistic Imperialism. Oxford: Oxford University Press, 1992.

RAJAGOPALAN, K. Política de ensino de línguas no Brasil: história e reflexões prospectivas. In: MOITA LOPES, L. P. (Org.). Linguistica Aplicada na Modernidade Recente: Festschrift para Antonieta Celani. São Paulo: Parábola, 2013. p.143-161.

RAJAGOPALAN, K. Por uma linguística crítica: linguagem, identidade e a questão ética. São Paulo: Parábola, 2004. 
RAJAGOPALAN, K. O inglês como língua internacional na prática docente. In: LIMA, D. C. (Org.). Ensino e aprendizagem de língua inglesa: conversa com especialistas. São Paulo. Parábola Editorial, 2009, p. 39-46.

ROBINS, K. Global times: what in the world is going on?London: Sage, 1997

SILVA, L.S. et al. Base nacional comum curricular: uma proposta de educação intercultural para o ensino de língua inglesa no Brasil. In: Seminário Gepráxis, Vitória da Conquista. Universidade Estadual do Sudoeste da Bahia: UESB, v.6, n.6, p. 2360-2375, 2017.

SCHMITZ, J. R. O inglês como língua internacional, globalização e o futuro de outras línguas e culturas: uma reflexão. Investigações, Recife, v. 17, n. 2, p. 223-242, jul. 2004.

SIQUEIRA, D. S. P. World Englishes, world English, inglês como língua internacional, inglês como lingual franca. In: LAGARES, X. C.; BAGNO M. (Org.). Políticas da norma e conflitos linguísticos. São Paulo: Parábola Editorial, 2011, p. 333-354.

Recebido em: 30/07/2018. Aprovado em: 22/08/2018. 